\title{
Helping blind and partially sighted people to read: the effectiveness of low vision aids
}

\author{
Tom H Margrain
}

\begin{abstract}
Aims-To substantiate the claim that low vision aids reduce the degree of disability associated with visual impairment. Methods-An observational study of vision, ocular pathology, age, sex, and reading ability in new referrals to a low vision clinic. Reading ability was assessed both with the patients' own spectacles and with an appropriate low vision aid.

Results-The reading performance and biographical characteristics of new referrals to a low vision clinic were recorded. Data were collected for 168 people over a 6 month period. Upon arrival at the clinic the mean functional visual acuity equated to $6 / 36$ and $77 \%$ of patients were unable to read newsprint (N8). After a low vision assessment and provision of a suitable low vision aid $88 \%$ of new patients were able to read N8 or smaller text.

Conclusions-The degree of visual impairment observed in new referrals to a low vision clinic is sufficient to prevent the majority from performing many daily tasks. Low vision aids are an effective means of providing visual rehabilitation, helping almost nine out of 10 patients with impaired vision to read.

(Br F Ophthalmol 2000;84:919-921)
\end{abstract}

The number of people with impaired sight that cannot be improved with the use of spectacles or other treatments is growing. Current estimates suggest that there are about one million people in the UK who could be registered blind or partially sighted. ${ }^{1}$ This estimate is supported by community based surveys which have shown that around $20 \%$ of those aged 75 and over have visual acuity less than $6 / 12 .^{2{ }^{3}}$ Demographic trends suggest that the numbers of people with impaired vision are likely to increase at least until 2021 because the main causes of low vision are age related. ${ }^{4}$

Medical intervention is unlikely to reduce significantly the numbers of people with impaired vision in the foreseeable future because there is currently no treatment for the primary cause of visual impairment, age related macular degeneration (ARMD).${ }^{56}$ Furthermore, although advances in the management of conditions such as glaucoma and diabetes are likely to reduce the number of people presenting with visual loss attributable to these conditions the overall numbers of people presenting with impaired sight is likely to grow. This is because all the major causes of blindness are age related and there is a general trend towards increased life expectancy.
Given that it will not be possible to cure visual impairment the emphasis must be on providing an effective rehabilitative "low vision service". Unfortunately, evidence shows that low vision service provision in the UK is a lottery. ${ }^{7}$ Some areas have a comprehensive service and others none at all. Furthermore, it appears that up to two thirds of people who would benefit from this service do not have access to it. ${ }^{8}$ Recently, the Low Vision Services Consensus Group made a number of recommendations about future low vision service delivery in the UK. ${ }^{9}$ These recommendations centre on the need for a comprehensive multidisciplinary approach to low vision and are likely to play an important part in shaping low vision service delivery in the UK. Although such an approach is likely to be successful there is little quantitative evidence about the effectiveness of such a service. This lack of evidence may be one of the main reasons why the low vision service is poorly developed in the UK.

One aspect of a comprehensive low vision service is the provision of suitable low vision aids. These devices help people to read and are likely to be beneficial because the inability to read is the chief complaint of patients with impaired vision. ${ }^{10}$ However, even the benefits of low vision aids are poorly recognised. ${ }^{11}$ This is not surprising, as there have been relatively few studies of the effectiveness of low vision aids. Those that have been conducted have used survey techniques to evaluate the performance of low vision aids, and they have not objectively quantified the reading performance before and after low vision aid provision. ${ }^{12}{ }^{13}$

The purpose of this study was to quantify the improvement in reading performance associated with the use of low vision aids.

\section{Subjects and methods}

Data were collected over a 6 month period from October 1997 to March 1998 from all new referrals to the Cardiff University low vision clinic. This clinic provides low vision services in South Wales to patients referred by the University of Wales College of Medicine.

Each patient had a low vision assessment. This involved the taking of history and symptoms, detailed questioning about the patients' visual requirements, assessment of their visual performance, refraction and an evaluation of the effect of magnification on their reading vision., This information was used to help to identify a suitable low vision aid.

Visual performance was evaluated using the Bailey-Lovie logMAR chart. This chart has a number of advantages over the conventional
Accepted for publication 26 April 2000 
Table 1 Biographical characteristics of new referrals to a low vision clinic

\begin{tabular}{lrc}
\hline Category & No & $\%$ \\
\hline Age & & \\
$10-19$ & 2 & 1.2 \\
$20-29$ & 3 & 1.8 \\
$30-39$ & 9 & 5 \\
$40-49$ & 6 & 3.4 \\
$50-59$ & 14 & 8.3 \\
60-69 & 32 & 19 \\
$70-79$ & 78 & 46.4 \\
$80-89$ & 18 & 10.7 \\
90-99 & 1 & 0.6 \\
>100 & & \\
Sex & 62 & 37 \\
Male & 106 & 63 \\
Female & & \\
Ocular disease: & 98 & 58.3 \\
Age related maculopathy & 11 & 6.5 \\
Glaucoma & 10 & 6 \\
Diabetic retinopathy & 7 & 4.2 \\
Myopic degeneration & 4 & 2.4 \\
Nystagmus & 4 & 2.4 \\
Optic atrophy & 3 & 1.8 \\
Cataract & 31 & 18.4 \\
Other & & \\
Binocular visual acuity: & 10 & 6 \\
6/6 to 6/9 & 41 & 24.4 \\
6/12 to 6/18 & 56 & 33.3 \\
6/24 to 6/36 & 34 & 20.2 \\
6/48 to 3/36 & 18 & 10.8 \\
3/60 to 2/60 & 8 & 4.8 \\
1/36 to 1/60 & 1 & 0.6 \\
less than 1/60 & & \\
\hline & & \\
\hline
\end{tabular}

Snellen chart and is particularly well suited to evaluation of impaired vision. ${ }^{14}$ In particular, it is possible to equate acuities obtained at different distances. This advantage is less relevant in assessments of near vision performance because it is seldom necessary to recalculate reading acuity for different distances. Therefore, reading performance was determined using the reading test types as approved by the Faculty of Ophthalmologists. This standardised text uses the Times New Roman typeface and is a widely accepted functional test of reading acuity. ${ }^{14}$
Without a low vision aid

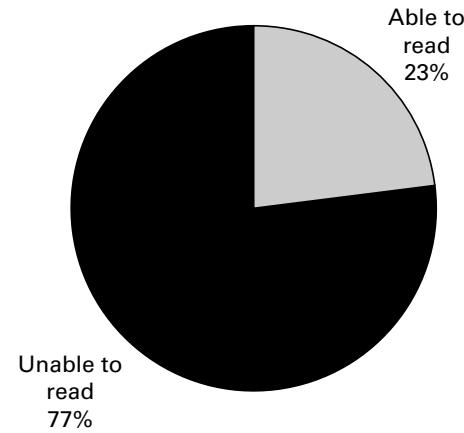

With a low vision aid

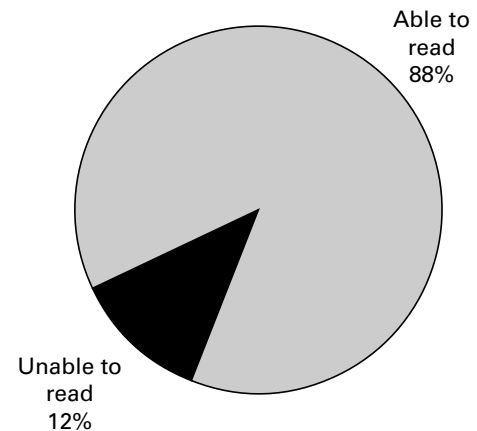

Figure 1 Pie charts showing the fraction of new referrals who could read newsprint (N8 or better) with reading spectacles but without the use of a low vision aid (left) and the fraction that could read with a low vision aid (right).

Table 2 Characteristics of low vision aids supplied (where appropriate, magnification is described in terms of mean maximum magnification - that is, F/4+1)

\begin{tabular}{lll}
\hline Description of aids & Aids supplied (\%) & Magnification \\
\hline High power reading addition & 13 & 7 dioptres \\
Hand magnifier & 20 & $\times 4$ \\
Illuminated hand magnifier & 20 & $\times 4.7$ \\
Stand magnifier & 6 & $\times 4$ \\
Illuminated stand magnifier & 30 & $\times 6.4$ \\
Other & 11 & not applicable \\
\hline
\end{tabular}

All new referrals were accompanied by a letter from the referring ophthalmologist stating the diagnosis. Information about the patients' ocular condition along with their age, sex, visual acuity before and after refraction, and their reading performance with reading spectacles both with and with out an appropriate low vision aid was recorded. The data were analysed on computer using a software package (sPSS Ver 7.5).

\section{Results}

In total data were collected from all 168 new referrals to the low vision clinic over the 6 month period of this investigation. The biographical characteristics of the patients are summarised in Table 1 .

Although the low vision clinic saw patients from almost all age groups (range 12-103 years) the vast majority $(83 \%)$ were over retirement age (65 years). The mean age of low vision patients was 76 years.

For ease of interpretation data about visual performance recorded using the Bailey-Lovie $\log$ MAR chart were converted to the equivalent Snellen fraction and are also presented in Table 1. Patients attending the low vision clinic for the first time had a mean binocular visual acuity of only 6/36. Refraction improved binocular VA by one line or more in only 59 subjects. For this group the mean improvement in VA equated to an improvement from approximately $6 / 36$ to $6 / 18$.

Figure 1 shows that only $23 \%$ of new referrals to our low vision clinic could read standard newsprint sized text (N8) on arrival at the clinic, indeed $40 \%$ were unable to read large print (N14). After provision of suitable low vision aids there was a marked increase in the number of people who could read. Almost nine out of 10 people with impaired vision were able to read standard sized newsprint (N8 or better) with the appropriate low vision aid. Low vision aids significantly improved reading ability (Wilcoxon signed rank test, two tails, $\mathrm{p}<0.0001)$.

Of those people whose vision improved to $\mathrm{N} 8$ or better $58 \%$ had ARMD, $6 \%$ had glaucoma, $6 \%$ diabetic retinopathy, and 5\% myopic degeneration. This distribution is almost identical to the original sample. The mean presenting visual acuity and reading vision of this group was $6 / 48$ (range $1 / 60$ to 6/9) and N17 (range N48 to N9) respectively.

Table 2 describes the types and powers of the magnifying devices used to bring about the improvement in reading ability. All devices were supplied on a loan basis free of charge in accordance with guidelines on best practice.

\section{Discussion}

The results of this study clearly show that low vision aids are an effective means of improving reading ability in people with impaired vision. The improved reading performance addresses the primary complaint of the majority of patients with ARM and it is perhaps for this reason that previous studies examining the effectiveness of low vision aid provision have 
reported that more than eight out of 10 patients reported a benefit from attending a low vision clinic. ${ }^{12}$

The observation that the pathology profile of the group whose vision was improved to N8 or better, was virtually identical to the original sample suggests that the benefit of low vision aid provision is not dependent on underlying pathology.

In common with many eye clinics, this study only evaluated reading performance in terms of ability to read $\mathrm{N}$ type print rather than reading speed or duration (reading fluency was noted descriptively but such data are not readily amenable to analysis - for example, "N10 with ease"). However, even if text of a particular size cannot be read fluently for long periods thus allowing reading for pleasure, it still provides access to essential material-for example, bills and bank statements which equate to about N8.

The vast majority of people who attend a low vision clinic for the first time have a significant degree of visual impairment; almost eight out of 10 are unable to read normal print and almost seven out of 10 have a binocular visual acuity below $6 / 18$. This finding is of some concern because people with such poor vision are likely to experience considerable difficulty in performing many daily tasks. Furthermore, these difficulties are likely to have been experienced for some time because many of the causes of visual impairment progress slowly and insidiously. Undoubtedly, there are many people in the community whose visual loss goes unrecorded..$^{15}$ There may be several reasons why people with impaired vision do not attend the low vision clinic at an earlier stage, the patient may fail to recognise the degree of visual impairment, ${ }^{17}$ fear of treatment, ${ }^{18}$ the stigma of blindness, ${ }^{19}$ and differences in ophthalmological referral criteria. ${ }^{20}$ An additional reason might be that, because there is no treatment for conditions such as age related maculopathy, it is perceived that little can be done to help people with impaired vision. This study clearly shows that this is not the case and that low vision aids help people with impaired vision to read.

The author would like to thank JC Greatrex and R Earlam who helped to collect the data.

1 Bruce I, McKennell A, Walker E. Blind and partially sighted adults in Britain: the RNIB survey. Volume 1. London: HMSO, 1991

2 Wormald RPL, Wright LA, Courtney P, et al. Visual problems in the elderly population and implications for services. BMF 1992;304:1226-9.

3 Lavery JR, Gibson JM, Shaw DE, et al. Vision and the visual acuity in an elderly population. Ophthalmic Physiol Opt $1988 ; 8: 390-3$

4 Office for National Statistics. Population: by age, 19612021. In: Social trends 29. London: Stationery Office, 1999

5 Ciulla TA, Danis RP, Harris A. Age-related macular degeneration: a review of experimental treatments. Surv Ophthalmol 1998;43:134-46.

6 Leibowitz H, Krueger D, Maunder L, et al. The Framingham Eye Study monograph: An ophthalmological and epidemiological study of cataract, glaucoma, diabetic retinopathy, macular degeneration, and visual acuity in a general population of 2631 adults, 1973-1975. Surv Ophthalmol 1980;24:335-610

7 Ryan B, Culham L. Fragmented vision; survey of low vision services in the UK. London: Royal National Institute for the Blind, 1999.

8 Lomas GM. Low vision in the UK toward a framework for delivering low vision care. London: The Partially Sighted Society, 1998.

9 Low Vision Services Consensus Group. Low vision services; recommendations for future service delivery in the UK. .

10 Virtanen P, Laatikainen L. Low-vision aids in age-related macular degeneration. Curr Opin Ophthalmol 1993;4:33-5.

11 Margrain TH. Minimising the impact of visual impairment. BMF 1999;318:1504.

12 Leat SJ, Fryer A, Rumney NJ. Outcome of low-vision aid provision - the effectiveness of a low vision clinic. Optom Vis Sci 1994;71:199-206.

13 Bischoff P. Long-term results of low-vision rehabilitation in age related macular degeneration. Doc Ophthalmol 1995;89: 305-11

14 Farrall H. Optometric management of visual handicap. London: Blackwell Scientific Publications, 1991

15 Robinson R, Deutsch J, Jones HS, et al. Unrecognized and unregistered visual impairment. Br F Ophthalmol 1994:78: 736-40.

16 Reidy A, Minassian DC, Vafidis G, et al. Prevalence of serious eye disease and visual impairment in a north London population: population based, cross sectional study. BMf 1998;316:1643-6.

17 Long CA, Holden R, Mulkerrin E, et al. Opportunistic screening of visual acuity of elderly patients attending outpatient clinics. Age Ageing 1991;20:392-5.

18 Reinstein DZ, Dorward NL Wormald RP, et al. "Correctable undetected visual acuity deficit" in patients aged 65 and over attending an accident and emergency department. Br f Ophthalmol 1993;77:293-6.

19 Cullinan TR. Visual disability in the elderly. London: Croom Helm, 1986.

20 Keeffe JE, Loviekitchen JE, Taylor HR. Referral to low-vision services by ophthalmologists. Aust NZ $\mathcal{f}$ Ophthalmol 1996;24:207-14. 